International Journal of Osteoarchaeology

Int. J. Osteoarchaeol. 17: 619-626 (2007)

Published online 11 April 2007 in Wiley InterScience

(www.interscience.wiley.com) DOI: 10.1002/oa.902

\title{
Pathogenesis of Apical Periodontal Cysts: Guidelines for Diagnosis in Palaeopathology
}

\author{
G. J. DIAS, ${ }^{a *}$ K. PRASAD ${ }^{a}$ AND A. L. SANTOS ${ }^{b}$ \\ a Department of Anatomy and Structural Biology, University of Otago, New Zealand \\ b Departamento de Antropologia, Universidade de Coimbra, 3000-056 Coimbra, Portugal
}

ABSTRACT Apical periodontal cysts are benign lesions developing in relation to the apices of non-vital teeth due to inflammatory response from the infective pulp. These are epithelium-lined bony cavities containing fluid. Despite being widely reported in medical/dental literature, this common condition is poorly diagnosed and documented in the archaeological literature. We aim to clarify the correct terminology, demonstrate bony manifestations at different stages of pathogenesis of chronic periapical dental lesions into granuloma and apical periodontal cysts, and to describe diagnostic criteria which would provide practical guidelines for the diagnosis of these conditions.

Three identified skulls from the International Exchange Collection, housed in the Anthropological Museum at the University of Coimbra, are used to identify the progression of this condition from a small periapical granuloma to a large apical periodontal cyst with expansion of alveolar and facial bones. The pathogenesis of this condition is described, together with its surgical management in the early $20^{\text {th }}$ century in Portugal, which is the period in which these individuals lived. Confusion resulting from the different terminologies can be avoided if the term periapical granuloma is used to define apical bony lesions smaller than $3 \mathrm{~mm}$ at their maximum intra-bony diameter, and the term apical periodontal cysts for the larger lesions. We recommend that these terminologies and parameters be used as a standard in future studies. This will make inter-observer and inter-population comparisons more accurate. Copyright @ 2007 John Wiley \& Sons, Ltd.

Key words: granuloma; pulpitis; International Exchange Collection; Portugal

\section{Introduction}

A cyst is a pathological cavity lined with epithelium and having fluid or semi-solid contents, which has not been created by the accumulation of pus (Dias \& Tayles, 1997; Concise Colour Medical Dictionary, 1998). Cysts are relatively common in the maxilla and mandible, but their pathogenesis is poorly understood. They are divided into two main groups, depending on the suspected origin of the lining epithelium:

\footnotetext{
* Correspondence to: Department of Anatomy and Structural Biology, University of Otago, New Zealand.

e-mail: george.dias@anatomy.otago.ac.nz
}

(1) Non-odontogenic cysts: the epithelial lining is derived from sources other than the toothforming organ (Soames \& Southam, 1998).

(2) Odontogenic cysts: the epithelial lining is derived from the epithelial residues of the tooth-forming organ (Shafer et al., 1983). These can be further subdivided into developmental and inflammatory types based on their aetiology.

The current study focuses on cysts arising from an inflammatory origin. Aetiology of this condition is not a maldevelopment, but of an infective nature arising from the pulp cavity (Ortner, 2003) 'as a result of exposure of the pulp

Received 1 June 2005 Revised 1 February 2006 Accepted 31 October 2006 
to oral bacteria through caries, attrition or trauma' (Dias \& Tayles, 1997).

As a result of this aetiology, 'tumour-like masses of granulation tissue heavily infiltrated with inflammatory cells' (Dias \& Tayles, 1997), referred to as periapical granulomas, form in relation to the root canal opening at the apex of the offending tooth. This is one of the most common of all sequelae of pulpitis' (Shafer et al., 1983). If the irritation persists, it progresses into an apical periodontal cyst (Dias \& Tayles, 1997).

The periodontal cysts are formed by the proliferation of epithelial cell rests (of Malassez) (Alt et al., 1998; Langsjoen, 1998) produced by fragmentation of the epithelial root sheath (of Hertwig) of the tooth-forming organ (Shafer et al., 1983). However, these cysts are some times erroneously described as abscesses lined with epithelium (Langsjoen, 1998). In the literature a number of terms are used to describe periodontal cysts, such as periapical cyst (Alt et al., 1998), radicular cyst (Mendonça, 1921; Ortner, 2003), para-dental cysts or appendicular cyst (Mendonça, 1921).

Apical periodontal cysts are the most common cystic lesions in the jaws and are always associated with the apices of non-vital (Dias \& Tayles, 1997; Soames \& Southam, 1998), erupted teeth either in the maxilla or the mandible (Mendonça, 1921; Ortner, 2003). These are most common between the ages of 20 and 60 years (Soames \& Southam, 1998) and more frequent in the maxilla (Mendonça, 1921; Soames \& Southam, 1998), affecting any tooth (Mendonça, 1921). According to Chazel \& Mafart (2004), in contemporary populations the prevalence of apical lesions is between $0.8 \%$ to $5.2 \%$ of grossly carious teeth. When small they are frequently symptomless (Mendonça, 1921; Alt et al., 1998; Hillson, 2000) unless there is an acute exacerbation, which may rapidly progress to abscess formation (Dias \& Tayles, 1997). Usually these are discovered during routine radiological examination (Hillson, 2000). Once formed, periodontal cysts tend to continue to expand equally in all directions. The high osmolarity of the cyst contents and the semipermeable nature of the wall results in the movement of fluid from the surrounding tissues into the lumen, and the resulting increase in hydrostatic pressure causes it to expand (Soames \& Southam, 1998; Marx \& Stern, 2003; Figure 4). The rate of expansion has been estimated at approximately $5 \mathrm{~mm}$ in diameter per year (Soames \& Southam, 1998); expansion of the alveolar bone occurs as a result of this enlargement (Shafer et al., 1983), and ultimately may discharge through a sinus. However, the majority of periodontal cysts do not grow to exceed $5 \mathrm{~cm}$ in diameter (Soames \& Southam, 1998). Incidentally, the term residual cyst refers to a periodontal cyst that has remained in the jaw and failed to resolve following extraction of the involved tooth (Soames \& Southam, 1998).

In the palaeopathological literature, periapical lesions of the jaws and their diagnosis have not been dealt with in a systematic manner. Alt et al. (1998) stated: 'in skeletal remains, the distinction between periapical granuloma and radicular cysts is based mostly on the size of the lesion'. The demarcation point between periapical granuloma and a periodontal cyst is set at $3 \mathrm{~mm}$ of the bony lesion by Dias \& Tayles (1997). This size is largely based on the clinical experience in dealing with these lesions by one author [Dias], and the dimension is confirmed by radiographs published by Shafer et al. (1983). Other authors (Whaites, 1992; Goaz \& White, 1994) have used a $15 \mathrm{~mm}$ dividing line between periapical granuloma and cysts based on radiological investigation. However, Priebe et al. (1954) demonstrated that to distinguish between periapical granuloma and a cyst by radiographic means alone is extremely difficult.

Inadequate descriptions in the palaeopathological literature, leading to confusion in the identification of these lesions, would have led to the majority being erroneously diagnosed as 'abscess cavities' and to relatively few cases being reported as periodontal cysts. Thus, the focus of this article is to describe the pathogenesis of chronic periapical dental lesions into granuloma, and then into apical periodontal cysts by using three examples from an identified skull collection to demonstrate different stages of pathogenesis, and to describe the specific bony diagnostic criteria for these conditions. Moreover, medical records for these individuals and the management of apical periodontal cysts are described for the

Int. J. Osteoarchaeol. 17: 619-626 (2007)

DOI: $10.1002 / \mathrm{oa}$ 
early $20^{\text {th }}$ century in Portugal, the period during which these individuals lived.

\section{Material and methods}

The International Exchange Collection is one of three identified human osteological collections housed in the Anthropological Museum at the University of Coimbra. This particular resource comprises 1075 skulls (Rocha, 1995) and was established by Eusébio Tamagnini (1880-1972), Director of the Anthropological Section of the Natural History Museum between 1907-1950 (Areia \& Rocha, 1985). Selection criteria for these individuals are unknown, but the aim of the International Exchange Collection was, as the name indicates, for scientific interchanges with other institutions; however, this was never realised (Rocha, 1995).

This collection consist of 524 male and 551 female skulls, with ages ranging from 6 to 109 years, born from 1818-1892 and dying between 1915-1938 (Rocha, 1995). Relevant information for each of the individuals was collected during the formation of the collection. Thus, the following reliable and comprehensive recorded data are available: place of birth of the Portuguese individuals, date of birth, sex, age at death, date of death, place of death, cause of death, occupation, marital status, name and parents' names, the source which was the Conchada Municipal Cemetery, the position of burial in the cemetery, and the 'remittance' number which probably corresponds to the order in which these individuals were entered into the collection (Santos, 2000).

For this research, three specimens revealing different stages of pathogenesis of apical periodontal cysts were selected. According to the collection records, skull number 21 belongs to a housewife, born in Coimbra and who died in 1927 at the age of 84 due to rheumatic myocarditis and syncope; the second skull (number 32) belongs to a male aged 43 years, born and resided in Forno Telheiro (Guarda) and admitted to Coimbra University Hospital suffering from intestinal occlusion which resulted in death in 1927; and the third individual from this sample (number 90) was a male, aged 40 years, born in Viseu and died in Coimbra in 1927 from pulmonary tuberculosis.

These skulls were examined with the naked eye under good lighting conditions and the sizes of the lesions were measured using a caliper and a curved probe. The width of the lesion was measured at the central (widest) part of the bone cavity.

\section{Results}

Bone lesions occurring in these three skulls are used to elaborate the morphology at different stages of pathogenesis of apical dental lesions from a granuloma to a periodontal cyst.

\section{Skull 37}

The maxilla is partially edentulous, and the teeth present on the right side are the incisors, the root of the canine, the second premolar and second molar. On the left side, incisors, canine, second premolar and second molar are present. The periodontal condition is poor and there are two interproximal caries present on the left second premolar and right second molar. The mandible has the right incisors, canine, first premolar and third molar, and left incisors, first premolar and first molar. The other molars were lost antemortem while the other missing teeth were lost peri- or post-mortem. Interproximal caries are found in five teeth.

An apical intra-bony cavity is present in relation to the apex of the septic root of the maxillary right canine. The related premolar has been lost ante-mortem. A breach in the buccal plate (resorption or post-mortem break) measuring $3 \times 2 \mathrm{~mm}$ leads into the internal bone cavity, with approximate dimensions from the hole of: superiorly $4 \mathrm{~mm}$, inferiorly $3 \mathrm{~mm}$, laterally and medially $2 \mathrm{~mm}$ (Figure 1 ). The measurements were taken with a curved probe. Remodelling and new bone formation is seen around the buccal bony breach.

Int. J. Osteoarchaeol. 17: 619-626 (2007)

DOI: $10.1002 /$ oa 


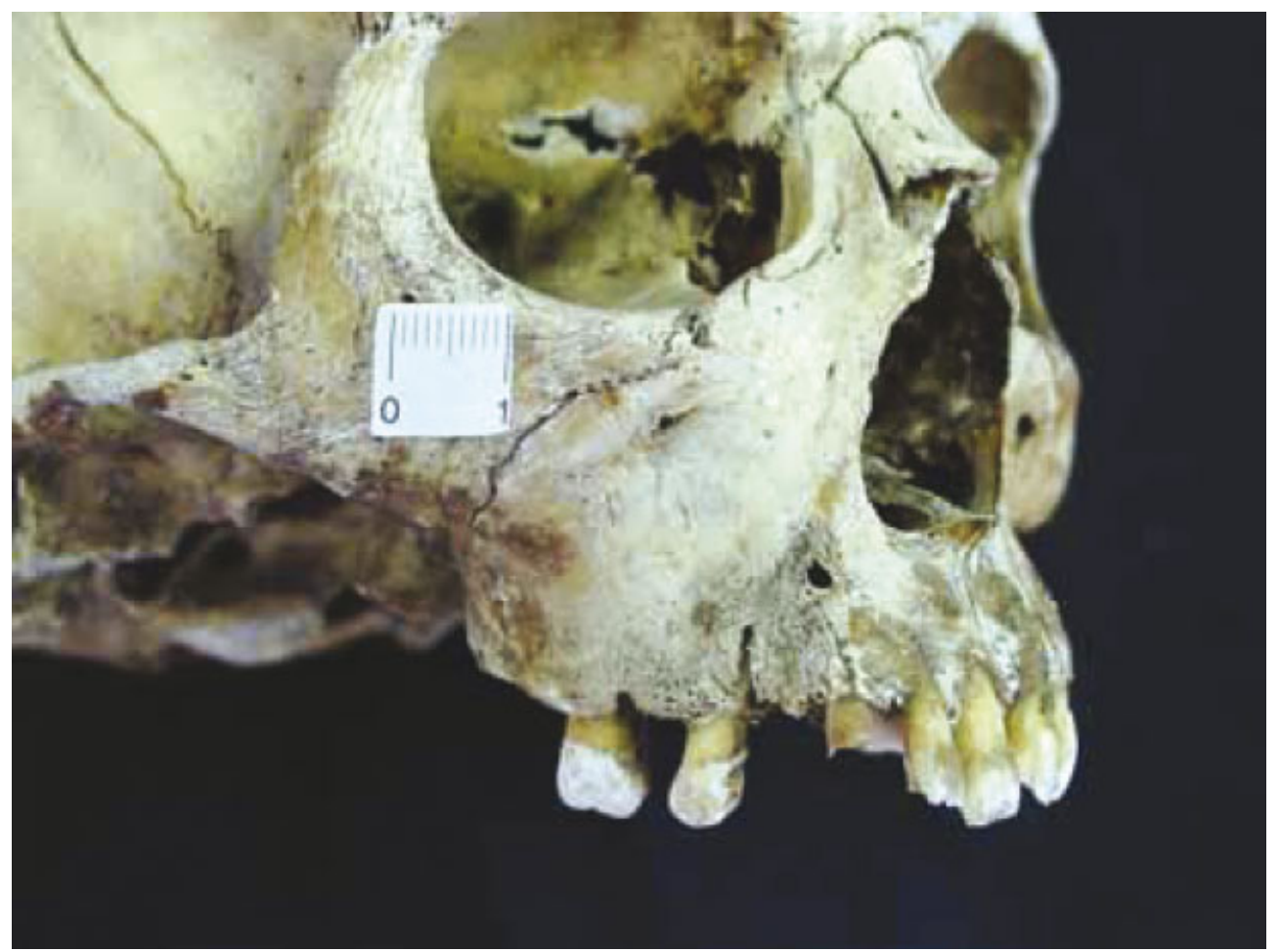

Figure 1. Oblique lateral view of skull 37 showing the right maxilla. The opening on the facial surface of the alveolar bone in relation to the apex of the septic root of the canine is seen $(2 \times 2 \mathrm{~mm})$. Surrounding the aperture there are signs of bone remodelling. (This is an example of a periapical granuloma, relating to stages A and B in Figure 4). This figure is available in colour online at www.interscience.wiley.com/journal/oa.

\section{Skull 90}

The male skull is partially edentulous both due to post-mortem damage and tooth loss. The upper teeth present are the right canine, and the left canine which is malpositioned and partially erupted, with the crown tilted mesially, and the three left molars.

In the lower jaw the left lateral incisor and first molar, and the right second premolar, first and third molars are present. The periodontal condition is poor with gross root exposure. A large hollow bony lesion $17 \mathrm{~mm}$ high and $10 \mathrm{~mm}$ wide is found in relation to the septic roots of the left maxillary second premolar tooth (Figure 2). The apical two-thirds of the root projects into the cavity. On the facial surface of the maxilla, the margins of the bony cavity show signs of outward expansion. The interior bony wall of the cavity is well demarcated, smooth and rounded. There is no perforation into the maxillary air sinus. No palatal expansion or perforation is seen.

\section{Skull 21}

The female skull has a full complement of teeth except the left upper and lower first molars, lost respectively ante- and post- or peri-mortem, since the alveolar bone in relation to the lower first molar sockets do not show gross bony resorption. There is post-mortem loss of the upper two central incisors, and the right upper and lower lateral incisors. There are signs that, in the past, attempts had been made to attach the teeth to the sockets with a white coloured glue. Ante-mortem fractures in the palatal cusps of the upper right second premolar and first molar are present. Occlusal caries in the upper left first premolar had completely destroyed the occlusal region of the crown down to the pulp cavity, and small interproximal caries are present in the lower 


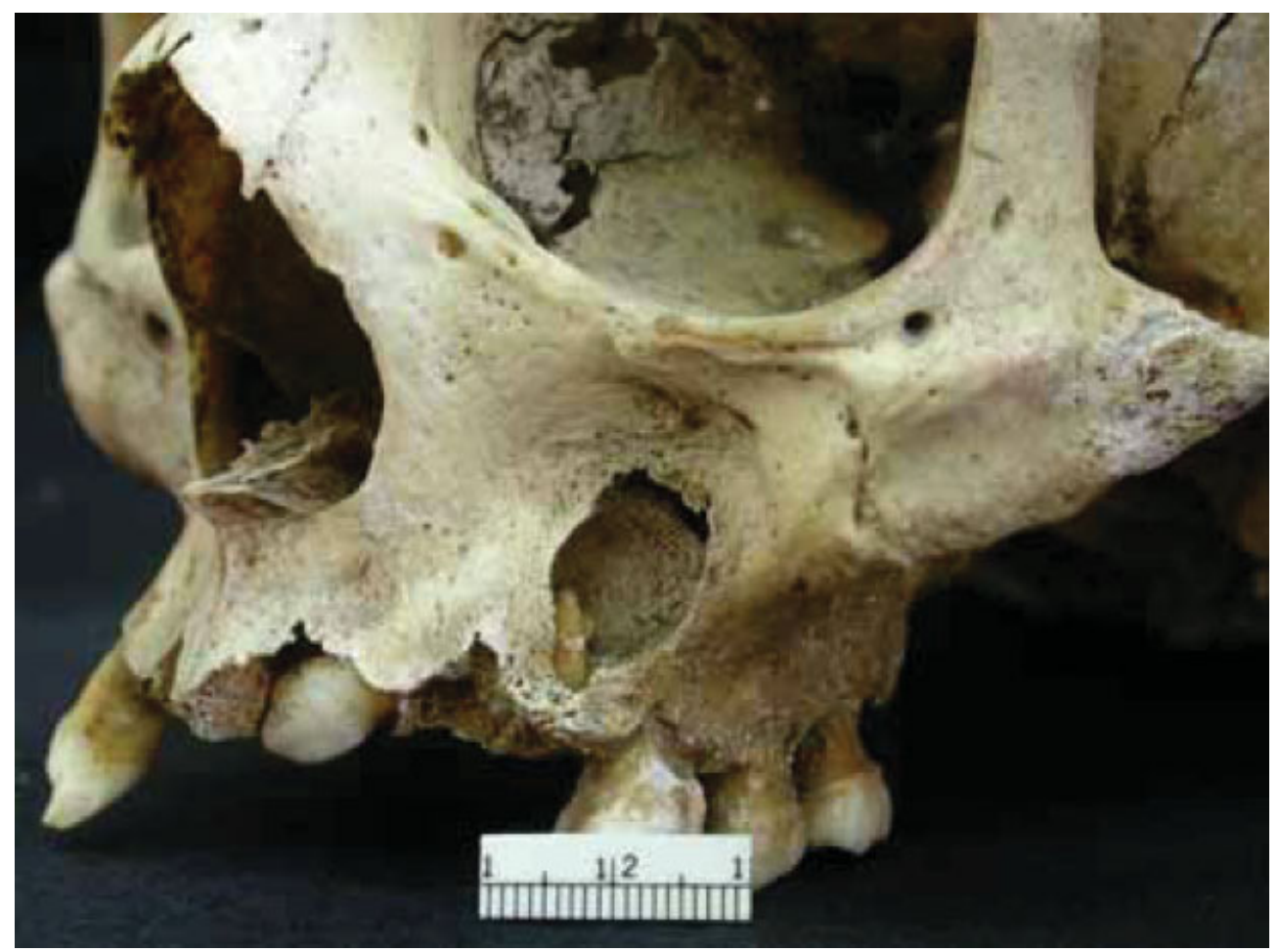

Figure 2. Lateral view of the left maxilla of skull 90, showing the bone lesion together with the root of the offending second premolar protruding into the bony cavity. The first premolar was lost ante-mortem and the canine is impacted. (This is an example of a moderate size apical periodontal cyst and relates to stages $D$ and $E$ in Figure 4). This figure is available in colour online at www.interscience.wiley.com/journal/oa.

right first molar. In general, she had good periodontal condition with no signs of gross vertical or horizontal alveolar crestal bone destruction.

There is a large hollow bony lesion present on the facial surface of the left maxilla (Figure 3 ) in relation to canine, first and second premolars. Perforation of bony wall on the facial surface extends vertically from around $6 \mathrm{~mm}$ superiorly from the alveolar margin, to around $3 \mathrm{~mm}$ inferior to the infra-orbital foramen, and medially up to $7 \mathrm{~mm}$ to the lateral nasal aperture. The gross appearance of the bony margins does not indicate this to be a destructive bone lesion caused by a malignant tumour or by an infective process, but rather to be caused by a slow-growing benign lesion. The walls of the bony cavity are smooth and well demarcated with no evidence of erosion/ moth-eaten appearance nor a multilocular soapbubble appearance. There is outward bulging of the facial wall of the bone cavity due to the

Copyright (C) 2007 John Wiley \& Sons, Ltd. expansion of the lesion, causing deformity at the margin of the nasal aperture (Figure 3A). The interior of the lesion is more extensive (undermined) involving almost the entire anterior region of the maxilla, compared with the opening on the facial surface. A bony septum forming the medial wall of the lesion cavity separates it from the maxillary air sinus, and there is no evidence of communication between the two. Roots of the lateral incisor, canine, first and second premolars project into the cavity. The apex of the root of the first premolar is resorbed, but the roots of the other three teeth are intact, with evidence of hypercementosis in the apical regions (Figure 3B). Furthermore, the lateral incisor, canine and the second premolar appear to be vital, with the first premolar being non-vital due to pulp exposure. There is expansion of bone on the palatal surface (Figure $3 \mathrm{C}$ ) in relation to the lesion, together with bone loss approximately in the central part of palatal bone in the region of the above teeth.

Int. J. Osteoarchaeol. 17: 619-626 (2007) DOI: $10.1002 / \mathrm{oa}$ 
(A)

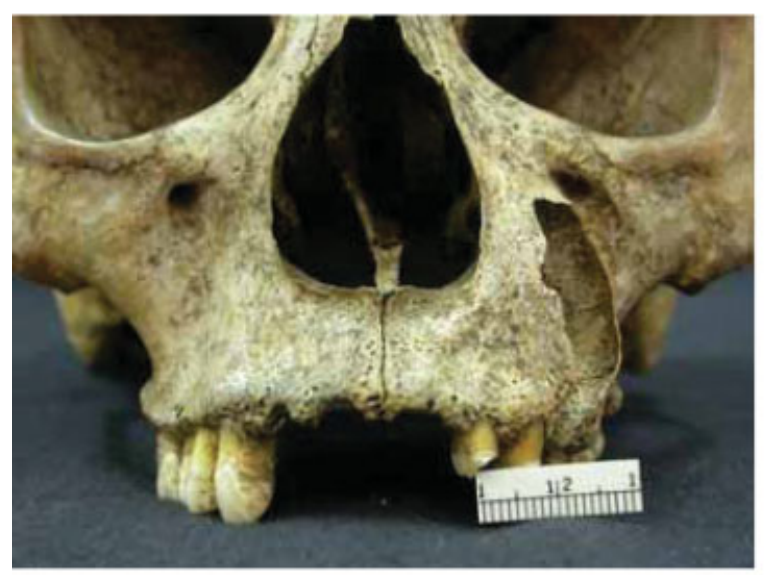

(C)

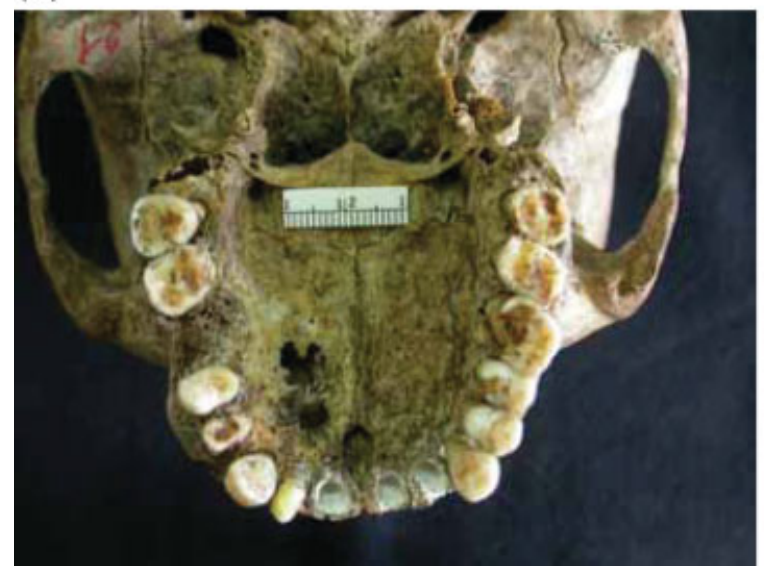

(B)

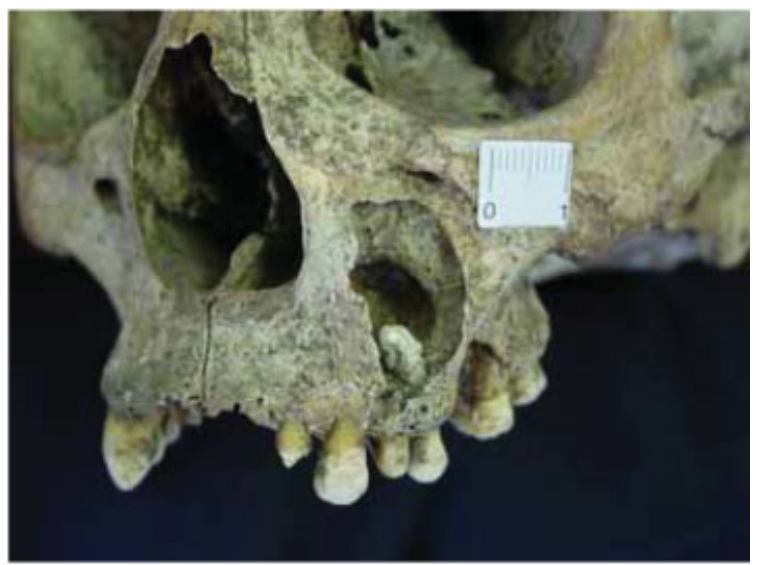

Figure 3. Skull 21 showing a large periapical periodontal cyst. (A) Anterior view of the skull showing the bony expansion of the left maxilla. (B) Oblique lateral view showing the extent of bone loss of the maxilla and the root of the second left premolar protruding into the bony cavity with no sign of resorption, together with hypercementosis at the apical region of the root. (C) Palatal expansion of the cyst leading to bone destruction. (This is an example of a late stage apical periodontal cyst and relates to Figure 4 stage $\mathrm{E}$ and beyond). This figure is available in colour online at www. interscience.wiley.com/journal/oa.

There are no signs of loosening of teeth adjacent to the above-mentioned teeth.

\section{Discussion}

The current study shows three stages of pathogenesis of a chronic dental apical lesion from a small granuloma to a large apical periodontal cyst (Figures 1 to 3 ). This process is diagrammatically illustrated in Figure 4. Periodontal cysts arise from the proliferation of epith- elial cell rests found within periapical granulomas, but not all granulomas progress to cysts (Soames \& Southam, 1998). At the granuloma stage (Figures 1 and 4A, B) if the infection source is eliminated (e.g. offending tooth is extracted) the condition will resolve, but once an apical periodontal cyst is established it will continue to expand, as represented in Figure $4 \mathrm{C}$ to $\mathrm{E}$, even if the source of chronic irritation is eliminated (Dias \& Tayles, 1997).

The expansion of the alveolar and facial bone in relation to these cysts is due to the deposition of successive layers of new bone by the overlying

Int. J. Osteoarchaeol. 17: 619-626 (2007)

DOI: $10.1002 /$ oa 


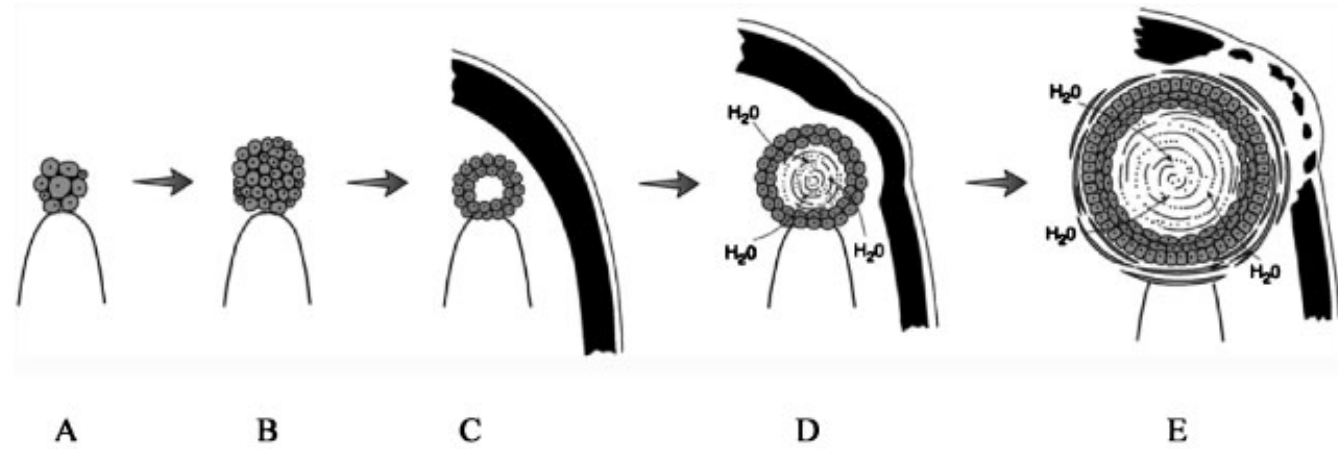

Figure 4. Diagrammatic illustration of pathogenesis of chronic periapical periodontitis. A and B illustrate the periapical granuloma stage. $\mathrm{C}$ - initial stage of an apical periodontal cyst formation (cyst is situated within the alveolar bone). D cyst of moderate size causing some outward expansion of alveolar bone. E-relatively large cyst causing the destruction of outer bone shelf and expanding into the surrounding soft tissue.

periosteum (Figure $4 \mathrm{D})$; as the cyst enlarges and causes bone resorption centrally, increments of new subperiosteal bone are laid down to maintain integrity of the cortex, producing a bony-hard expansion (Shafer et al., 1983; Soames \& Southam, 1998). However, the rate of expansion tends to outstrip the rate of subperiosteal deposition, leading to progressive thinning of the cortex (Figure 4E) which can be deformed on palpation, producing the clinical sign of 'oil-can bottom' or 'egg-shell crackling' (Soames \& Southam, 1998). In historical Portuguese clinical descriptions, the non-tender nature of this condition, the clinical sign of crepitation (egg-shell crackling) on palpation, and the fact that the lesion contained fluid were noted by Mendonça (1921). Furthermore, this surgeon described the expansion of these cysts into the maxillary air sinus and the nasal cavity.

Eventually the cyst may perforate the cortex and present as a bluish, fluctuant, submucosal soft-tissue swelling (Soames \& Southam, 1998) which will be the stage next to that of Figure 4E, resulting in facial deformity (Mendonça, 1921).

During the lifetime of the individuals described in this paper, the diagnosis and treatment of odontogenic cysts available in Portugal was as follows: the surgical approach was complete enucleation of the cyst wall to be carried out under local anesthesia (Mendonça, 1921); this may have been due to relatively high risks involved with general anaesthesia at the time.
The surgical principles used in early $20^{\text {th }}$ century are valid for today (complete enucleation of the cyst wall and primary closure).

In archaeological skeletal material this type of cyst may be seen without an obvious causative source of infection such as a septic tooth (Dias \& Tayles, 1997; Ortner, 2003). These have to be categorised as 'residual periodontal cysts' where the causative tooth/teeth have exfoliated and the socket has healed.

Contrary to the pathogenesis of this condition described by Alt et al. (1998), a certain amount of resorbtion of the root may occur at both stages of granuloma or apical periodontal cyst. This is associated with a certain degree of hypercementosis of the apex of the tooth (Figure 3 ).

This relatively common condition in oral pathology is nevertheless poorly reported in the archaeological literature where small lesions have been misdiagnosed as abscesses. Diagnosis of apical periodontal cysts is recommended for periapical bony cavities based on the presence of a source of infection in the pulp, the size and shape of the cavity, and the nature of its walls.

\section{Concluding comments}

The prevalence of apical periodontal lesions in archaeological populations remains unknown, since the diagnosis of these cysts has previously been made mainly with regard to large lesions. 
Lower frequency of these advanced stages could be the reason for the relatively small number of cysts being described in palaeopathological studies.

The variety of terminology for this condition is also a source of confusion. Based on the pathogenesis, it is recommended that bony lesions smaller than $3 \mathrm{~mm}$ at their maximum intra-bony diameter should be diagnosed as periapical granulomas, and the bony lesions larger than that as apical periodontal cysts. Finally, we hope that these recommended terminologies and bony parameters will be used as a standard in future studies. This will make inter-observer and inter-population comparisons more accurate.

\section{Acknowledgements}

Thanks are due to the Museum of Anthropology for allowing study of the collection, to Sofia Wasterlain at the University of Coimbra, and to Robbie McPhee at the Anatomy Department, University of Otago, for the drawings.

\section{References}

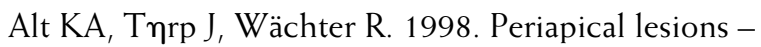
clinical and anthropological aspects. In Dental Antbropology: Fundamentals, Limits, and Prospects, Alt KA, Rsing FW, Teschler-Nicola M (eds). SpringerVerlag: Wien; 247-276.

Areia MLR de, Rocha MA. 1985. O ensino da antropologia. In Cem anos de Antropologia em Coimbra 1895-1995, Museu e Laboratório Antropológico (ed.). Museu e Laboratório Antropológico: Coimbra; $13-60$.
Chazel J-C, Mafart B. 2004. Apical lesions. British Dental Journal 196: 2-3.

Concise Colour Medical Dictionary. 1998. Oxford University Press: Oxford.

Dias G, Tayles N. 1997. 'Abscess cavity' - a misnomer. International Journal of Osteoarchaeology 7: 548-554.

Goaz PW, White SC. 1994. Oral Radiology: Principles and Interpretation. C.V. Mosby: St. Louis.

Hillson SW. 2000. Dental pathology. In Biological Antbropology of the Human Skeleton, Katzenberg MA, Saunders SR (ed.). Wiley-Liss: New York; 249286.

Langsjoen O. 1998. Diseases of the dentition. In Cambridge Encyclopedia of Human Paleopathology, Aufderheide AC, Rodríguez-Martín C (ed.). Cambridge University Press: Cambridge; 393412.

Marx RE, Stern D. 2003. Oral and Maxillofacial Pathology: A Rationale for Diagnosis and Treatment. Quintessence Publishing Company: Illinois.

Mendonça A. 1921. Quistos para-dentários. Direcção de Serviços Gráficos do Exército: Lisboa.

Ortner DJ. 2003. Identification of Pathological Conditions in Human Skeletal Remains. Academic Press: San Diego.

Priebe WA, Lazansky JP, Wuehrmann AH. 1954. The value of the roentgenographic film in the differential diagnosis of periapical lesions. Oral Surgery, Oral Medicine, Oral Pathology 7: 979-983.

Rocha MA. 1995. Les collections ostéologiques humaines identifiées du Musée Anthropologique de l'Université de Coimbra. Antropologia Portuguesa 13: 7-38.

Santos AL. 2000. A skeletal picture of tuberculosis: macroscopic, radiological, biomolecular, and bistorical evidence from the Coimbra Identified Skeletal Collection. PhD dissertation, Universidade de Coimbra.

Shafer WG, Hine MK, Levy BM. 1983. A Textbook of Oral Pathology. W.B. Saunders Company: Philadelphia.

Soames JV, Southam JC. 1998. Oral Pathology. Oxford University Press: New York.

Whaites E. 1992. Essentials of Dental Radiograpby and Radiology. Churchill Livingstone: Edinburgh. 